\title{
ERWIN WALTER PALM (1910-1988)
}

El profesor, doctor Erwin Walter Palm, nació en la ciudad de Frankfurt el año de 1910; ahí creció y pasó parte de su juventud e inició estudios de música con Klemen Krauss en el Conservatorio de dicha ciudad. Posteriormente, a nivel universitario, estudió filología, arqueología y filosofía clásicas e historia de la ciencia, en las Universidades de Gottingen, Heidelberg y Florencia, graduándose con una tesis sobre Ovidio.

En 1934, ya casado con la poetisa Hilde Domin, salió de Roma para Inglaterra, y en 1935 la pareja se trasladó a la República Dominicana, por obvias dificultades causadas por la guerra. Largos años habrían de vivir los Palm en ese país en donde él asimiló sólidos conocimientos sobre las culturas prehispánicas y la historia colonial. En Santo Domingo, el doctor Palm fue catedrático de arqueología clásica y de historia. En 1946, el gobierno dominicano lo distinguió con el nombramiento de Conservador de sus monumentos y obras de arte. En 1955 publicó su valiosa obra -en dos volúmenes-Monumentos Arqueológicos de la Española, que constituye la culminación de una serie de investigaciones que había hecho sobre asuntos históricos-artísticos hispanoamericanos y que debe considerarse básica para el conocimiento de la historia del arte en América. Durante esos años, hizo a la vez traducciones al alemán de poesías españolas y latinoamericanas, con las cuales formó un libro - ya famoso- titulado Rosa de Cenizas con el cual -a decir de uno de sus colegas- llegó de golpe a Alemania la literatura de todo un continente. Esta publicación tuvo lugar en 1958.

Sumamente informado y ya para siempre involucrado en la cultura hispanoamericana, Palm regresó a su patria en 1960. Fue entonces cuando ingresó como profesor en la Universidad de Heidelberg. Al correr del tiempo, movido por su espíritu universalista y por fidelidad a la cultura de su "segunda patria", Erwin Walter Palm -en colaboración con Districh Eckel- fund6, en el Instituto de Historia del Arte de Heidelberg, una sección de Historia del Arte Iberoamericano, dentro de un alto nivel interdisciplinario.

Su gran interés por la cultura mexicana se mostró claramente a partir de 1964 cuando se desempeñó como organizador y director del importante proyecto cultural, interdisciplinario, Puebla-Tlaxcala, de cuya intensa labor quedaron muchos estudios sobre dicha región, recogidos en el boletín titulado Comunicaciones. Además, las investigaciones hechas 
DOI: ttp://dx.doi.org/10.22201/iie.18703062e.1989.60.1546

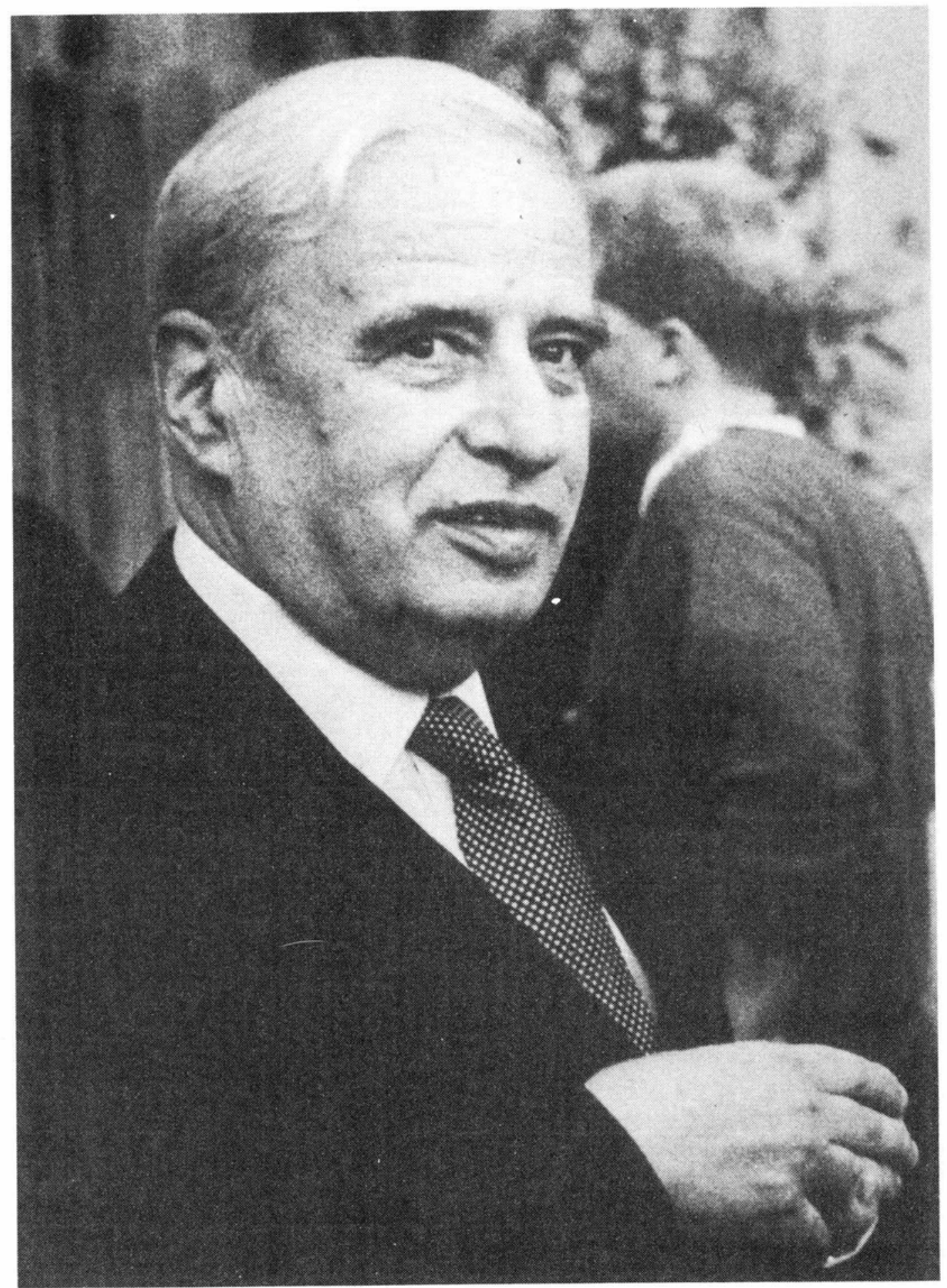

Erwin Walter Palm. 
dentro de ese proyecto, bajo los auspicios de la Fundación Alemana para la Investigación Científica, se comentaron también en Simposia, al menos en dos, el último de los cuales tuvo lugar en 1978. Con tal motivo Palm pasaba grandes temporadas en México y fue entonces cuando se estrechó su amistad con nuestro Instituto de Investigaciones Estéticas, para el que siempre mostró especial estimación.

Sus esfuerzos académicos se vieron premiados en 1975, cuando su Universidad le otorgó la categoría de Emérito, y en 1982, al ingresar como miembro de la Academia de Bellas Artes de Heidelberg.

Fue precisamente en ese mismo año de 1982 cuando el profesor Palm colaboró generosamente, con quien firma esta nota, en la organización del Simposio titulado Iconología y Sociedad: Arte colonial Hispanoamericano, el cual tuvo lugar dentro de las sesiones del Congreso de Americanistas que se celebró en la ciudad de Manchester, en septiembre de ese año. Un libro, fruto de dicho simposio, acaba de ser publicado por el Instituto de Investigaciones Estéticas. El Prólogo fue escrito por el doctor Palm, quien desafortunadamente ya no pudo asistir a dicho Congreso, por razones de salud. Ojalá que los ejemplares que se le enviaron de esta obra hayan llegado oportunamente a sus manos. A partir de ese momento la comunicación epistolar con él se volvió escasa y espaciada, pero nunca faltaron, mientras vivió, sus cariñosas letras de felicitación de fin de año.

Erwin Walter Palm falleció el 7 de julio de 1988 y descansa en el Cementerio de Heidelberg.

El polifacético talento de este ilustre intelectual incursionó también en el campo de la poesía. No sólo al emprender las traducciones arriba mencionadas, ni las que hizo de las poesías de su esposa, sino que él mismo escribió poesía y teatro; creaciones que sólo son - por ahoradel conocimiento de sus amigos más cercanos.

Por lo que respecta directamente al arte mexicano, hay que mencionar ante todo que Palm fue uno de los iniciadores de los estudios de la iconografía del arte novohispano. Sobresalientes muestras de este género son sus espléndidos, eruditos artículos sobre los murales de la Casa del Deán y sobre la Casa de los Muñecos; ambos edificios pertenecientes a la ciudad de Puebla.

No cabe duda de que el profesor Palm demostró ampliamente profundo interés, amor y comprensión por nuestra cultura. Su desaparición significa una irreparable pérdida para este Instituto, y en especial para 
los estudios del arte novohispano, pues él era uno de los colegas mayores del Viejo Mundo, con quien existía comunicación.

Elisa VARgas Lugo

\section{JAN BIALOSTOCKI}

(1921-1988)

En Varsovia, ciudad que le vio nacer, falleció el 25 de diciembre de 1988 el notable historiador del arte Jan Bialostocki, autor de una obra considerable formada por ensayos publicados en revistas especializadas y varios libros que le sitúan como un distinguido humanista. Sus participaciones en los congresos ordenados en torno de las obras de arte, así como las cátedras universitarias que atendió tanto en Europa como en los Estados Unidos de Norteamérica, resaltan su valía de manera idéntica con lo que publicó. Figuró también como Director del Instituto de Historia del Arte de la Universidad de Varsovia, y en el Museo Nacional de la capital polaca, fue curador de la Galería de Pintura Europea.

Jan Bialostocki profesó el método iconológico del inolvidable Erwin Panofsky; sus estudios más relevantes están comprendidos dentro de esa discipilna. En el libro Ars Auro Prior, publicado en Varsovia en 1981 en su honor, con motivo de sus sesenta años de edad, se reunieron 115 ensayos escritos por autores de distintos países; entre esas colaboraciones se encuentra la extensa bibliografía de cuanto había escrito, con esmerada entrega, hasta 1980; los temas que trató son múltiples, si bien predominan los referentes a la pintura. De esa labor sobresaliente, por desgracia un solo libro se ha publicado en español: Estilo e iconografía. Contribución a una ciencia de las artes (Barcelona, 1972). En el año de su muerte apareció en Viena su último libro: The Message of Images.

En diversas ocasiones fue huésped distinguido de la Universidad Nacional Autónoma de México; en julio de 1976 participó en el Coloquio Internacional de Historia del Arte, organizado por el Instituto de Investigaciones Estéticas.

Con la desaparición de Jan Bialostocki, la cultura de su patria ha sufrido una pérdida irreparable; otro tanto se puede afirmar respecto al mundo de las humanidades.

XAVIER MOYSSÉN 